\title{
Effects of Chemical Dispersant on the Surface Properties of Kaolin and Aggregation with Spilled Oil
}

\section{Wenxin Li ( $\sim$ I1149038579@dlmu.edu.cn )}

Dalian Maritime University https://orcid.org/0000-0003-2975-0254

\section{Yue Yu}

Dalian Maritime University

\section{Deqi Xiong}

Dalian Maritime University

\section{Zhixin Qi}

Dalian Maritime University

\section{Sinan Fu}

Dalian Maritime University

\section{Xinping Yu}

Dalian Maritime University

\section{Research Article}

Keywords: oil spill, chemical dispersant, wettability, oil-mineral aggregate, oil droplets size distribution, oil trapping efficiency

Posted Date: September 8th, 2021

DOl: https://doi.org/10.21203/rs.3.rs-671319/v1

License: (c) (i) This work is licensed under a Creative Commons Attribution 4.0 International License.

Read Full License

Version of Record: A version of this preprint was published at Environmental Science and Pollution Research on January 9th, 2022. See the published version at https://doi.org/10.1007/s11356-021-177462. 


\section{Abstract}

After oil spills occur, dispersed oil droplets can collide with suspended particles in the water column to form the oil-mineral aggregate (OMA) and settle to the seafloor. However, only a few studies have concerned the effect of chemical dispersant on this process. In this paper, the mechanism by which dispersant affects the surface properties of kaolin as well as the viscosity and oil-seawater interfacial tension (IFT $T_{\mathrm{ow}}$ ) of Roncador crude oil were separately investigated by small scale tests. The results indicated that the presence of dispersant impairs the zeta potential and enhances the hydrophobicity of kaolin. The viscosity of Roncador crude oil rose slightly as the dosage of dispersant increased while $I F T_{\text {ow }}$ decreased significantly. Furthermore, the oil dispersion and OMA formation at different dispersantto-oil ratio $(D O R)$ were evaluated in a wave tank. When $D O R$ was less than $1: 40$, the oil enhancement of dispersant was not significant. In comparison, it began to contribute when $D O R$ was over 1:40 and the effect became more pronounced with the increasing DOR. The adhesion between oil droplets and kaolin was inhibited with the increasing $D O R$. The size ratio between oil droplets and particles is the significant factor for OMA formation. The closer the oil-mineral size ratio is to 1, the more difficultly the OMA forms.

\section{Introduction}

With the increase of global demand for petroleum products and maritime transportation, many petroleum hydrocarbon contaminants entered the marine environment through various oil spill accidents ( $\mathrm{He}$ et al., 2018; Qi et al., 2018). Because of the toxic effect of oil on the aquatic ecology, it is necessary to clean it up in time once the oil spill accident occurs (French et al., 2004). The application of oil dispersant is a traditional means of oil spill removal (Prince and Butler, 2016). During the Deepwater Horizon spill in 2010, more than 2 million gallons of oil dispersant were sprayed onto the oil using aircraft and ships (McNutt et al., 2012; Hansel et al., 2015). The dispersant contain amphiphilic molecules ("surfactants") in a solvent base (Fernandes et al., 2019), and the surfactants break up the oil slick into micron-sized droplets, which are further carried below the water surface by waves. The oil is degraded by various micro-organisms present in the water column (Clayton et al., 1993; Li et al., 2008).

However, in estuaries and coastal waters, due to the high concentration of particulate matter in the water column and the strong shear effect of waves, dispersed oil droplets are easy to aggregate with suspended particulate matter to form the oil-mineral aggregate (OMA), thus leading to the sinking of spilled oil (Fitzpatrick et al., 2015; Silva et al., 2019). Under appropriate conditions, up to $20 \%$ of the spilled oil can interact with particulate matter, and the oil content of the formed OMA after spraying oil dispersant accounts for $65 \%$ of the total spilled oil (Bandara et al., 2011). As polycyclic aromatic hydrocarbons (PAHs) persist much longer in the sediment phase than at the sea surface (Harayama et al., 1999), these oil-bearing aggregates will exist on the seabed for a long time, resulting in excessive petroleum hydrocarbon contaminant, especially toxic PAHs, posing a serious threat to both the benthic communities and marine environment (Gao et al., 2019; Qi et al., 2021; Suneel et al., 2021). Common oil spill responses are mostly applicable to the floating oil but ineffective for the sunken oil (IMO, 2012; Usher, 2009). Remarkably, the sunken oil cannot be easily monitored by typical visual observation or 
remote sensing techniques (Yu et al., 2021; Hammoud et al., 2019), posing challenges to the cleaning operations (Jacqueline, 2008).

Except for the physical adsorption force, there may be a more potent chemical force between oil droplets and particles (Lambert and Variano, 2016), thus the morphological structure of OMA is usually stable. Zhao et al. (2017) analyzed the 3D structure of OMA using a confocal microscope imaging technology and found that particles could be embedded into the oil droplets at depth of 2-10 $\mu \mathrm{m}$. The factors that affect the OMA formation are very complex, such as oil characteristics (concentration, droplets size, viscosity, density and polar component), particulate matter characteristics (concentration, particle size, density, hydrophobicity, composition and zeta potential) and environmental conditions (temperature, salinity and mixing energy) (Loh et al., 2014; Gao et al., 2018). Many scholars have studied the above influencing factors on OMA formation and summarized some empirical results. Hua et al. (2018) proved that oil viscosity is a key factor affecting the aggregation process of oil and suspended particulate matter, lower oil viscosity was conducive to the stable formation of OMA. Moreira et al. (2015) found that polar components (asphaltenes and resins) in oil can improve the adhesion between oil droplets and suspended particles, thus contributing to the formation of OMA. Yu et al. (2019a) found that under the same mass concentration, more oil droplets can be trapped by smaller particles, and larger particles tend to interact more quickly with oil droplets. Strong hydrophobicity of solid particles can promote their affinity with the oil droplets, making them easier to form OMA (Loh and Yim, 2016). Unfortunately, it remains unknown which of the above factors has a more significant effect on the oil-mineral aggregation.

Besides, few studies have focused on the formation of OMA in the presence of chemical dispersant and related conclusions have been still a matter of controversy. Khelifa et al. (2008) proposed that in the marine environment where the mixing energy and suspended particulate concentration are usually low, the use of oil dispersant would be beneficial to the formation of OMA. The surfactants in the dispersant can significantly reduce the oil-water interfacial tension and viscosity, making the spilled oil disperse into a large number of emulsified droplets and maintain stable (Cai et al., 2017). Li et al. (2007) found that the synergistic effect of dispersant and mineral fines enhances the transfer of oil from the surface downward into the water column. However, some studies have found that excessive dispersant can inhibit the formation of OMA (Yu et al., 2019a; Sørensen et al., 2014; Page et al., 2002), but the specific cause has not been confirmed. Furthermore, previous studies often ignored the effect of dispersant on the physicochemical properties of oil and minerals, so this study will start from these aspects to fill the knowledge gap.

The overall goal of this study is to investigate the effect of chemical dispersant on the surface properties of minerals and spilled oil, and determine the mechanism of OMA formation in the presence of chemical dispersant. The specific objectives are to : 1) examine the variation of zeta potential, cation exchange capacity $(C E C)$ and contact angle $(C A)$ of minerals, viscosity of oil and oil-water interfacial tensions (IFT ow) with dispersant-to-oil ratios $(D O R), 2)$ evaluate the dispersion and sedimentation of oil with 
medium viscosity in a wave tank at different $D O R$, and 3) analyze the influencing factors of the OMA formation.

\section{Materials And Methods \\ 2.1. Materials}

The Roncador crude oil from Brazil was selected in this study due to its excellent sinking performance. The density and kinematic viscosity $\left(v_{\mathrm{k}}\right)$ were determined using a petroleum densitometer (SY-05, Guangzhou WanMu Instrument Equipment Co., Ltd, Foshan City, China) and kinematic viscosimeter (BF03C, Dalian North Analytical Instrument Co., Ltd, Dalian, China), respectively. The IFT ow was measured by an Automatic Surface Tensiometer (BZY-101) referring to the standard (GB 6541 -1986). The content of asphaltene and sulfur were measured according to the standard methods (NB/SH/T 0509-2010). Detailed physicochemical properties are summarized in Table 1.

Table 1

A summary on the properties of Roncador

\begin{tabular}{|lllll|}
\hline $\begin{array}{l}\text { Density } \\
\left(20^{\circ} \mathrm{C}\right),\end{array}$ & $\begin{array}{l}\mathrm{v}_{\mathrm{k}}\left(20^{\circ} \mathrm{C}\right), \\
\mathrm{mm}^{2} / \mathrm{s}\end{array}$ & $\begin{array}{l}\text { IFT ow } \\
\mathrm{mN} / \mathrm{m}\end{array}$ & $\begin{array}{l}\text { Asphaltene content, } \\
\mathbf{\%}\end{array}$ & $\begin{array}{l}\text { Sulfur content, } \\
\%\end{array}$ \\
$\mathbf{g} / \mathrm{cm}^{3}$ & & 31.73 & 4.41 & 1.76 \\
\hline 0.9433 & 1579.65 & 3 & & \\
\hline
\end{tabular}

The white kaolin purchased from Andi Metal Materials was selected in this study owing to its wide distribution in the marine environment. The particle size was measured by a laser-diffraction instrument (LISST-100X; Sequoia, Seattle, WA), and the mean size was $12.46 \mu \mathrm{m}$.

The chemical dispersant used in this study was GM-2, a non-ionic oil spill dispersant provided by the Qingdao Guangming Environmental Protection Technology Co. The surfactant is mainly fatty alcohol polyoxyethylene ether and the solvent is polyethylene glycol. Detailed physicochemical properties are summarized in Table 2.

Table 2

A summary on the properties of GM-2

\begin{tabular}{|lll|}
\hline $\mathrm{pH}$ & Ignition point, ${ }^{\circ} \mathrm{C}$ & $\boldsymbol{U}_{\mathbf{k}}\left(\mathbf{3 0 ^ { \circ }} \mathrm{C}\right), \mathrm{mm}^{2} / \mathbf{s}$ \\
\hline $7-7.5$ & 70 & 50 \\
\hline
\end{tabular}

The seawater was obtained from Xinghai Bay, Dalian, China ( $39^{\circ} 5^{\prime} 51.65^{\prime \prime} \mathrm{N}$ and $\left.121^{\circ} 50^{\prime} 95.19^{\prime \prime} \mathrm{W}\right)$ with a salinity of $30 \%$ o. Before each experiment, it was filtered through $0.45 \mu \mathrm{m}$ pore.

\subsection{Modification method}




\subsubsection{Modification of kaolin}

Briefly, $300 \mathrm{~mL}$ seawater and $3 \mathrm{~g}$ kaolin were added into a $500 \mathrm{~mL}$ baffled flask, leading to a particle concentration of $10 \mathrm{mg} / \mathrm{mL}$. After fully mixing, certain amounts of chemical dispersant were added based on a series of dispersant-to-mineral ratios $(D M R)$. $D M R$ were set to 1:150, 1:75, 1:38, 1:30 and 1:15, respectively. Then the dispersant-kaolin-seawater mixtures were shaken at $200 \mathrm{rpm}$ in a reciprocating shaker for $12 \mathrm{~h}$. The supernatants were discharged after the mixtures were left for $6 \mathrm{~h}$ at $15^{\circ} \mathrm{C}$. The bottom modified kaolin (MK) was repeatedly washed by deionized water and dried at $50^{\circ} \mathrm{C}$ for $12 \mathrm{~h}$.

\subsubsection{Modification of oil viscosity}

According to different $\operatorname{DOR}(0,1: 100,1: 50,1: 10,1: 8$, and 1:5), $15 \mathrm{~g}$ fresh oil and a certain quality of dispersant was stirred evenly in a $100 \mathrm{~mL}$ beaker, placed in an oscillator to shake for $30 \mathrm{~min}$, and then left for $6 \mathrm{~h}$ at $15^{\circ} \mathrm{C}$ in a standing incubator. The viscosity of oil was measured using the viscometer (BF-03C, North Dalian, China) and the capillary viscometer ( $\varphi=2 \mathrm{~mm}$, the viscometer constant is $\left.1.024 \mathrm{~mm}^{2} / \mathrm{s}^{2}\right)$. The measurement was repeated at least three times for each sample.

\subsubsection{Modification of the $I F T_{\text {ow }}$}

$50 \mathrm{~mL}$ seawater and $0.1 \mathrm{~g}$ Roncador crude oil were added into a $100 \mathrm{~mL}$ beaker. A series of O/W emulsions were prepared according to different $\operatorname{DOR}(0,1: 400,1: 200,1: 150,1: 100,1: 60,1: 40,1: 20$, and $1: 10)$ using the magnetic stirrers. After stirring for $30 \mathrm{~min}$, the samples were left for $6 \mathrm{~h}$ at $15^{\circ} \mathrm{C}$. The $I F T_{\text {ow }}$ were measured using the automatic surface tensiometer (BZY-101, SHfangrui, China). The measurement was repeated at least three times for each sample.

\subsection{Analytical methods}

\subsubsection{Analysis of Zeta potential}

The zeta potential of kaolin and MK was measured using the zeta potentiometer (JS94J2M, Global Hengda Scientific, Beijing, China). The measurement was repeated at least three times for each sample.

\subsubsection{Analysis of $C E C$}

CEC mainly characterizes the exchangeability between the cations on the surface of particles and those in solution, and also plays an important role in the expansion of minerals. $C E C$ was determined by the barium clay method: 1) $0.3 \mathrm{~g}$ minerals were added in a dry $10 \mathrm{~mL}$ centrifuge tube, weighed as $g_{1}(\mathrm{~g})$. Then $5 \mathrm{~mL}$ of $\mathrm{BaCl}_{2}$ solution $(0.5 \mathrm{~mol} / \mathrm{L})$ were added into it and vibrated for $1 \mathrm{~min}$, centrifuged at 10,000 rpm for 5 min and the supernatant was sucked out. Distilled water was added for centrifugation at 10,000 rpm for $5 \mathrm{~min}$, and the supernatant was sucked out. The total weight of the centrifuge tube and wet minerals was denoted as $\left.g_{2}(\mathrm{~g}) ; 2\right) 7 \mathrm{~mL}$ of $\mathrm{H}_{2} \mathrm{SO}_{4}$ solution $(0.025 \mathrm{~mol} / \mathrm{L})$ were added in the centrifuge tube and vibrated for $1 \mathrm{~min}$, then centrifuged at 10,000 rpm for $5 \mathrm{~min}$, and $5 \mathrm{~mL}$ of the supernatant were sucked to a conical flask; 3 ) three droplets of phenolphthalein indicator were dropped into the conical flask, titrated until the solution kept red with $\mathrm{NaOH}$ solution $(0.05 \mathrm{~mol} / \mathrm{L})$. The volume of $\mathrm{NaOH}$ solution 
consumed was denoted as $V_{2}(\mathrm{~mL})$; 4) $5 \mathrm{~mL}$ of $\mathrm{H}_{2} \mathrm{SO}_{4}$ solution $(0.025 \mathrm{~mol} / \mathrm{L})$ were added in a new conical flask and step 3) was repeated. The volume of $\mathrm{NaOH}$ solution consumed was denoted as $V_{1}$ $(\mathrm{mL}) . C E C(\mathrm{mmol} / 100 \mathrm{~g})$ was calculated by:

$$
\mathrm{CEC}=100\left[7 \times \mathrm{N} \times \mathrm{V}_{1}-(7+\mathrm{L}) \times \mathrm{N} \times \mathrm{V}_{2}\right] / 5 \mathrm{~m} \#(1)
$$

where $N$ is the concentration of $\mathrm{NaOH}$ solution $(0.05 \mathrm{~mol} / \mathrm{L}), L$ is the humidity correction term $\left(g_{2}-g_{1}, \mathrm{~g}\right), m$ is the mass of kaolin $(0.3 \mathrm{~g})$.

\subsubsection{Analysis of $C A$}

The $C A$ of kaolin and MK was measured using the optical contact angle measuring instrument (Theta Flex, Biolin Scientific, Finland). The measurement was repeated at least three times for each sample.

\subsection{Oil-mineral aggregation experiments}

\subsubsection{Wave tank facility}

In this study, the oil dispersion and oil-mineral aggregation experiments were individually conducted in a mesoscale wave tank. Figure 1 illustrates the schematic of the wave tank facility. The dimensions were $1.5 \mathrm{~m}$ long, $0.3 \mathrm{~m}$ wide, and $0.5 \mathrm{~m}$ high. The temperature of seawater was adjusted to $15^{\circ} \mathrm{C}$, and the average water depth was $0.20 \mathrm{~m}$. A motor-driven push-type wavemaker was situated at one end of the tank to generate waves. Furthermore, a wave absorber was placed oppositely to control the reflection of the waves.

The wave energy in this tank is quantitatively characterized by the turbulent kinetic energy (TKE) and energy dissipation rate $(\varepsilon)$, which were calculated as follows (Shen and Maa, 2017) :

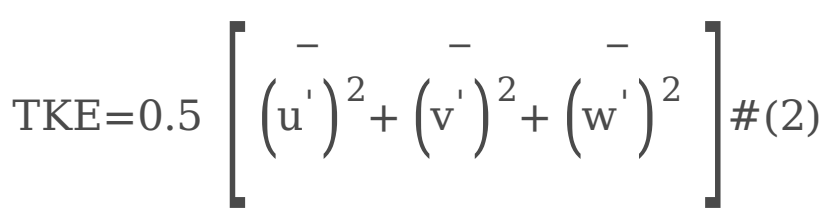

where $u^{\prime}, v^{\prime}$ and $w^{\prime}$ are velocity fluctuations in $x, y$ and $z$ directions, with $u^{\prime}=u-U, v^{\prime}=v-V$ and $w^{\prime}=w-$ $W$, respectively, and the overbar denotes the time average within the time duration $T$.

$$
\varepsilon=(2 \pi / \mathrm{u}) \cdot(\mathrm{C} / \mathrm{A})^{3 / 2} \#(3)
$$

where $C$ is the reading of energy at $f=1 \mathrm{~Hz}$ from the least square fitted line with a fixed slope of $-5 / 3$ in the log-log plot of $E(f)$ vs. $f$. $A$ is the Kolmogorov universal constant selected as 0.7 (Liu et al., 2011). Calculated by Eq. (2) and Eq. (3), TKE and $\varepsilon$ were $7.9 \times 10^{-3} \mathrm{~m}^{2} / \mathrm{s}^{2}$ and $9.7 \times 10^{-3} \mathrm{~m}^{2} / \mathrm{s}^{3}$, respectively.

\subsubsection{Oil droplets size measurement}


In this study, the oil droplets size distribution $(O S D)$ and volume concentration of emulsified oil $\left(V_{\text {oil }}\right)$ were measured by a laser-diraction instrument (LISST-100X, Type C, Sequoia Scientific, Seattle, WA, USA) situated $100 \mathrm{~cm}$ downstream from one side of the tank with the detection windows $7 \mathrm{~cm}$ below the surface. It was operated in real-time mode and the dynamic oil-droplet size distribution was acquired every $3 \mathrm{~s}$. The volumetric mean diameter $(V M D)$ of the oil droplets was calculated by:

$$
\mathrm{VMD}=\left(\sum \mathrm{v}_{\mathrm{i}} \cdot d_{i}\right) / V \#(4)
$$

where $V$ is the total volume concentration, and $v_{i}$ is the volume concentration of oil droplets in a size interval with average size $d_{i}$

\subsubsection{Experimental procedures}

The dispersed oil concentration in the water column was measured by an on-line monitor (E09 TD4100XDC, Turner Designs Hydrocarbon Instruments, Fresno, CA, USA). The sampling time was set as 1, 5, $10,20,30,40,60,90$ and 120 min, respectively. There were 6 sampling points, represented by red dots in Fig. 1 (two different depths and three horizontal locations). According to the pre-experiment, DOR for the wave tank experiment was set as $0,1: 400,1: 100,1: 40,1: 20$ and 1:10, respectively. Firstly, $9 \mathrm{~g}$ of kaolin were added into the wave tank with a particle concentration of $100 \mathrm{mg} / \mathrm{L} .20 \mathrm{~g}$ of Roncador crude oil and a certain quality of dispersant was added to the water surface, then the wave-making plate was started to make the oil droplets and minerals fully mixed and collided. The wave-making plate was stopped after two hours of operation and left standing for $12 \mathrm{~h}$ to make the formed OMA settle to the bottom naturally. After the oil slick on the surface was removed, the upper liquid was extracted with a vacuum pump until the remaining water depth was between $3-5 \mathrm{~cm}$. Then all the sediments were removed and transferred to the separation funnel; $50 \mathrm{~mL}$ of $\mathrm{n}$-hexane and $2 \mathrm{~mL}$ of dilute sulphuric acid were added. The funnel was constantly shaken for $5 \mathrm{~min}$, and left standing for $10 \mathrm{~min}$. The extract was filtered through micro-fiberglass filters and dried with anhydrous sodium sulfate, analyzed by absorbance $(A)$ at a wavelength of $225 \mathrm{~nm}$ with UV spectrophotometry (Epoch 2, BioTek, Winooski, VT, USA) (Yu et al., 2019b). The function of the standard curve of petroleum hydrocarbons concentration for Roncador crude oil $(C)$ was: $A=$ $0.0325 C+0.0029\left(R^{2}=0.9999\right)$. The oil trapping efficiency $($ OTE $)$ was used to quantitatively assess the OMA formation:

$$
\mathrm{OTE}=\left(\mathrm{m}_{1} / \mathrm{m}_{2}\right) \times 100 \backslash \% \#(5)
$$

where $m_{1}$ is the mass of the sunken oil $(\mathrm{g}), m_{2}$ is the mass of the dispersed oil in the water column at 120 $\min (\mathrm{g})$.

\section{Results And Discussion}

\subsection{Effects of dispersant on the surface properties of kaolin}


Figure 2 shows the change of zeta potential and CEC of kaolin with various dosages of dispersant. With the increase of $D M R$ from 0 to $1: 75$, the value of zeta potential decreased from $-64.36 \pm 1.15$ to $-42.63 \pm$ $2.02 \mathrm{mV}$, while $C E C$ had no significant change. As $D M R$ continued to increase, the decline of zeta potential was no longer apparent, while $C E C$ showed an initial increase followed by a drop. Overall, the magnitude of variation in $C E C$ was not obvious. The minimum and maximum value was $8.68 \pm 0.41$ and $12.11 \pm 0.63$ $\mathrm{mmol} / 100 \mathrm{~g}$, respectively. The evolution of the zeta potential versus $D M R$ was consistent with Cai et al. (2017), in which that increasing DMR from 0 to 1:10 modestly suppressed the zeta potential of the OS sediments (collected from the Ocean Springs National Seashore Park) from - 15.5 to $-13.5 \mathrm{mV}$. The reason for this phenomenon is that the non-ionic surfactant in the dispersant is adsorbed to the surface of the particle and then has a shielding effect on the surface potential of the particle (Yoon et al., 2014). Besides, due to the directional induction of hydrophilic groups and lipophilic groups, the compressing double-layer process of particles is promoted to some extent, which leads to the migration of surface charge, so the self-polymerization phenomenon between particles becomes significant (Kang et al., 2019). For these reasons, the space of hydration film was effectively enlarged, leading to the increase of $C E C$. However, when the concentration of chemical dispersant was high, the cationic surfactant would be adsorbed onto the surface of particles and form a hydrophobic interfacial film with a certain strength. Thus the osmotic expansion process was gradually arrested, and the swelling of particles was effectively inhibited (Murtaza et al., 2020). The ion exchange between the particle surface and water phase was inhibited by the hydrophobic interfacial film. Simultaneously, the interlayer space was also compressed, and the channel for the cation exchange became narrow. Both of them directly led to the decrease of $C E C$.

As shown in Fig. 3, the contact angle (CA) of kaolin increased from $11.78^{\circ}$ to $37.89^{\circ}$ as $D M R$ rose from 0 to $1: 15$, which indicated that the kaolin became more hydrophobic. This was also caused by the formation of hydrophobic interfacial film after the addition of chemical dispersant. The larger the dosage of dispersant, the greater the strength of interface film, and the higher the corresponding hydrophobicity.

\subsection{Effects of dispersant on the oil viscosity and oil-water interfacial tension}

The oil viscosity $\left(U_{\text {oil }}\right)$ after addition of dispersant was assessed at DOR of $0,1: 100,1: 50,1: 10,1: 8$ and 1:5, respectively (Fig. 4a). As DOR increased from 0 to $1: 10, v_{\text {oil }}$ increased from $208.38 \pm 1.04$ to $225.28 \pm$ $4.31 \mathrm{~mm}^{2} / \mathrm{s}$ at $50^{\circ} \mathrm{C}$ and from $65.54 \pm 1.66$ to $74.75 \pm 4.09 \mathrm{~mm}^{2} / \mathrm{s}$ at $80^{\circ} \mathrm{C}$, respectively. However, when $D O R$ continued to grow, $v_{\text {oil }}$ at $50^{\circ} \mathrm{C}$ remained stable, while $v_{\text {oil }}$ at $80^{\circ} \mathrm{C}$ continued to increase. When $D O R$ increased from 0 to 1:5, the increase in oil viscosity ranged from $8-34 \%$. This result was consistent with Khelifa et al. (2008), in which the increase in crude oil viscosity was $15 \%$ with the presence of dispersant. The oil viscosity reflects the intermolecular friction and is closely related to the size and structure of molecules (Baled et al., 2018). Asphaltene molecules in oil have a crystal structure similar to graphite. A large number of polymers can form through the intermolecular forces such as charge transfer, hydrogen bond and dipole interaction, and stably exist in the lamellar interlayer of asphaltene molecules (Shi et al., 2021; Fajardo-Rojas et al., 2020). This is also the main reason for the high viscosity of the oil. Because 
dispersant is mainly composed of surfactants and solvent with strong permeability, we speculate that the surface-active agent may make the polymer in the interlayer space of the asphaltene molecules more closely and orderly arranged, and indirectly increase the stability of the asphaltene flake structure. The intermolecular friction increased accordingly, leading to a higher $v_{\text {oil }}$. However, the temperature has a more significant effect on the oil viscosity, and the viscosity decreases rapidly with the increase of oil temperature. Oil with good viscosity-temperature characteristic has a smaller range of viscosity varying with temperature.

IFT $T_{\text {ow }}$ after addition of dispersant was studied at different DOR (Fig. 4b). IFT ow significantly decreased from $38.70 \pm 1.01$ to $10.13 \pm 1.02 \mathrm{mN} / \mathrm{m}$ with the increase of dispersant dosage in the DOR range of $0-$ 1:20. When $D O R$ exceeded 1:20, no significant change of IFT ow was observed. It is well known that when dispersant is sprayed on the oil slick, the surfactant molecules are immediately adsorbed on the oil-water interface (Kujawinski et al., 2011). The lipophilic group extends to the oil phase while the hydrophilic group extends to the aqueous phase, making the IFT ow greatly reduced and an interfacial film with certain strength forms. Brandvik et al. (2019) compiled data from several earlier studies and found that IFT ow decreased logarithmically with the increase of dispersant dosage, which was consistent with the results obtained in this experiment.

\subsection{Effects of dispersant on the oil dispersion and OMA formation}

As shown in Fig. 5 , the dispersed oil concentration $\left(C_{\text {oil }}\right)$ increased first and then stabilized with time in each condition with the presence of the dispersant. The more the dispersant was applied, the higher the $C_{\text {oil }}$ was. In the absence of dispersant, $C_{\text {oil }}$ changed very little and fluctuated in the range of $10-20 \mathrm{mg} / \mathrm{L}$. When DOR was between 0 and 1:40, $C_{\text {oil }}$ increased slowly with time and reached the maximum value at $90 \mathrm{~min}$, then remained stable. The maximum $C_{\text {oil }}$ at $D O R$ of 1:40 was 2.5 times higher than that without dispersant. When DOR was 1:20 and 1:10, $C_{\text {oil }}$ both increased rapidly with time and reached the maximum at $90 \mathrm{~min}$ of $143.56 \mathrm{mg} / \mathrm{L}$ and $169.88 \mathrm{mg} / \mathrm{L}$, respectively. This phenomenon was attributed to the chemical dispersant that stimulated the dispersion of two-ring and multiple-ring aromatic fractions of oil into the bulk aqueous phase (Li et al., 2007).

As shown in Fig. 6, the $V M D$ of oil droplets under different conditions all decreased with time. However, the decay rate of $V M D$ gave a slightly different result. When $D O R$ was 1:400, the $V M D$ decreased to $128.04 \mu \mathrm{m}$ at $60 \mathrm{~min}$ and then reduced slowly to $120.65 \mu \mathrm{m}$ at $120 \mathrm{~min}$. A similar variation trend was also observed when $D O R$ was 1:100. When DOR was over 1:100, the $V M D$ decreased rapidly within 10 min. The more the dispersant was applied, the smaller the $V M D$ was. When $D O R$ was $1: 10$, the $V M D$ decreased from $87.06 \mu \mathrm{m}$ to $40.80 \mu \mathrm{m}$ within $10 \mathrm{~min}$ and then fell to $31.05 \mu \mathrm{m}$ at $120 \mathrm{~min}$. Li et al. (2017) found that oil dispersant and suspended sediment can promote oil dispersion into the water column either individually or together through the wave tank experiment, and the presence of oil dispersant can 
reduce the average particle size of oil droplets from 150-200 $\mu \mathrm{m}$ to $50 \mu \mathrm{m}$. The larger the dispersant dosage, the smaller the IFT $T_{\text {ow, }}$ making the oil droplets more easily dispersed.

Figure 7 shows the $O S D$ curve at $1 \mathrm{~min}$ and 120 min with different $D O R$. The $O S D$ curve was unimodal at $1 \mathrm{~min}$, and the higher the $D O R$, the smaller the peak value of $V M D$. When $D O R$ was 1:400 and 1:100, the $O S D$ curves were both bimodal at $120 \mathrm{~min}$, but transformed into unimodal when $D O R$ increased. The peak values were $32.50,27.60$ and $23.40 \mu \mathrm{m}$ at $120 \mathrm{~min}$ when $D O R$ was 1:40, 1:20 and 1:10, respectively. When DOR was $1: 10$, the oil droplet size mainly concentrated between 12 to $32 \mu \mathrm{m}$ at $120 \mathrm{~min}$, close to the average size of kaolin $(12.46 \mu \mathrm{m})$. Brandvik et al. (2013) observed that the peak value of dispersed oil droplets size distribution decreased significantly after adding dispersant, which was consistent with the results of this study.

Several studies have found that the addition of oil dispersant is helpful to the formation of OMA (Li et al., 2020 , Loh et al., 2020). Unexpectedly, the OMA formation was gradually inhibited with the increase of dispersant dosage in this experiment (Fig. 8). When dispersant was not applied, the OTE was $28.59 \%$, and fell to $0.34 \%$ when $D O R$ was $1: 20$. While the dispersant does not directly affect the partitioning of individual components (or groups of components) to the water phase, it does reduce the affinity of the oil droplets to the suspended particulate matter (Sørensen et al., 2014). Sørensen et al. (2014) considered that the reduction in adsorption of oil to suspended particulate matter might be attributed to the surfactants in the dispersant stabilizing the smaller oil droplets in the water column (and thus counteracting adsorption to particulates). However, other studies have found that chemical dispersant can promote the aggregation of oil with montmorillonite, quartz sand, and other particles to form OMA (Bandara et al., 2011; Khelifa et al., 2005). Therefore, Roncador crude oil and kaolin should be aggregated by adhesion force to form OMA. Although the chemical dispersant effectively promotes the dispersion of spilled oil and increases the oil concentration in the water column, it also dramatically reduces the size of the dispersed oil droplets, making the size between the minerals and the oil droplets closer. Since OMA majority performed as an oil droplet coated uniformly by small minerals (oil droplets larger than minerals) (Yu et al., 2019a; Qi et al., 2020), the closer the size of oil droplets is to that of minerals, the more difficult it is to form OMA.

The decrease of zeta potential and the increase of hydrophobicity of minerals should have promoted the aggregation of oil and particle, but the opposite result was obtained. Therefore, these are not the dominant factors for the formation of OMA. CEC fluctuated with the increase of dispersant dosage, so it could not make a sustained reduction in the formation of OMA. Dispersant could increase oil viscosity, which would have inhibited the formation of OMA. However, due to the low temperature in this study, dispersant had little effect on oil viscosity, so it was not the main reason for the significant reduction of OMA formation. The decrease of $I F T_{\text {ow }}$ made the oil more easily dispersed into the water column and increased the chance of collision and aggregation between oil droplets and minerals, so the decrease of OMA formation was not caused by the reduction of IFT $T_{\text {ow }}$. The oil-mineral particle size ratio tended to be the major influencing factor for the formation of OMA. In addition, with the increase of dispersant dosage, the dissolved oil content in the water column increased significantly. In contrast, the number of emulsified 
oil droplets decreased, and the adhesion between oil and minerals was inhibited, which significantly reduced the formation of OMA.

\section{Conclusions}

This study first investigated the effect of chemical dispersant on the surface properties of kaolin and Roncador crude oil. Then, its further influence on the oil dispersion and OMA formation was studied through a mesoscale experiment. With the increase of dispersant concentration, the zeta potential of kaolin decreased gradually, and the decay rate was from fast to slow. By comparison, cation exchange capacity increased first and then decreased, but the overall change was not significant; and the hydrophobicity increased continuously. The viscosity of Roncador crude oil increased as dispersant dosage increased, and the variation trend was more obvious at high temperature. The oil-seawater interfacial tension decreased significantly and remained stable as dispersant dosage increased. Chemical dispersant promoted the dispersion of oil spills in water column and reduced the oil droplets size. Meanwhile, it also inhibited the aggregation between oil droplets and kaolin as DOR increased, owing to the decrease of the number of emulsified oil droplets. Compared to other factors, the OMA formation is mainly affected by the size difference between oil droplets and minerals. The closer the two sizes are, the more difficult it is to form OMA.

\section{Declarations}

\section{Ethics approval and consent to participate}

Not applicable

\section{Consent for publication}

Not applicable

\section{Availability of data and materials}

The datasets used and/or analysed during the current study are available from the corresponding author on reasonable request.

\section{Competing interests}

The authors declare that they have no competing interests.

\section{Funding}

This study was supported by National Natural Science Foundation of China (42076167, 41807466), the Fundamental Research Funds for the Central Universities (3132019148), the Liaoning Provincial Natural 
Science Foundation of China (20170540099) and the Double First Class Construction (innovation) Project (BSCXXM027).

\section{Authors' contributions}

LW: laboratory experiments, writing - original draft, writing - review \& editing; YY: validation, data curation; XD: conceptualization, resources; QZ: methodology, supervision; FS: laboratory experiments; YX: laboratory experiments.

\section{Acknowledgments}

The authors are grateful to the Dalian Branch of China Inspection \& Certification Group Liaoning Co., Ltd for providing Roncador crude oil.

\section{References}

1. Baled HO, Gamwo IK, Enick RM, McHugh MA (2018) Viscosity models for pure hydrocarbons at extreme conditions: A review and comparative study. Fuel 218:89-111. https://doi.org/10.1016/j.fuel.2018.01.002

2. Bandara UC, Yapa PD, Xie H (2011) Fate and transport of oil in sediment laden marine waters. J Hydro-Environ Res 5:145-156. https://doi.org/10.1016/j.jher.2011.03.002

3. Brandvik PJ, Daling PS, Leirvik F, Krause DF (2019) Interfacial tension between oil and seawater as a function of dispersant dosage. Mar Pollut Bull 143:109-114. https://doi.org/10.1016/j.marpolbul.2019.04.019

4. Brandvik PJ, Johansen O, Leirvik F, Farooq U, Daling PS (2013) Droplet breakup in subsurface oil releases - Part 1: Experimental study of droplet breakup and effectiveness of dispersant injection. Mar Pollut Bull 73(1):319-326. https://doi.org/10.1016/j.marpolbul.2013.05.020

5. Cai ZQ, Fu J, Liu W, Fu KM, O'Reilly SE (2017) Effects of oil dispersants on settling of marine sediment particles and particle-facilitated distribution and transport of oil components. Mar Pollut Bull 114(1):408-418. https://doi.org/10.1016/j.marpolbul.2016.09.057

6. Fajardo-Rojas F, Pradilla D, Solano O, Samaniuk J (2020) Probing interfacial structure and dynamics of model and natural as-phaltenes at fluid-fluid interfaces. Langmuir 36:7965-7979. https://doi.org/10.1021/acs.langmuir.0c01320

7. Fernandes JC, Agrawal NR, Aljirafi FO, Bothun GD, McCormick AV (2019) Does the solvent in a dispersant impact the efficiency of crude-oil dispersion? Langmuir 35(50):16630-16639. https://doi.org/10.1021/acs.langmuir.9b02184

8. Fitzpatrick FA, Boufadel MC, Johnson R, Lee KW, Graan TP, Bejarano AC, Zhu Z, Waterman D, Capone DM, Hayter E (2015) Oil-particle interactions and submergence from crude oil spills in marine and freshwater environments: Review of the science and future research needs. US Geological Survey 
9. French MD, Rowe JJ, Whittier N, Sankaranarayanan S, Schmidt ED (2004) Estimation of potential impacts and natural resource damages of oil. J Hazard Mater 107:11-25.

https://doi.org/10.1016/j.jhazmat.2003.11.013

10. Gao YL, Xiong DQ, Qi ZX, Li XS, Ju ZL, Zhuang XQ (2019) Distribution of polycyclic aromatic hydrocarbons in sunken oils in the presence of chemical dispersant and sediment. J Mar Sci Eng 7(9). https://doi.org/10.3390/jmse7090282

11. Gao YL, Zhao X, Ju ZL, Yu Y, Qi ZX, Xiong DQ (2018) Effects of the suspended sediment concentration and oil type on the formation of sunken and suspended oils in the Bohai Sea. Environ Sci-Proc Imp 20(10):1404-1413. https://doi.org/10.1039/c8em00293b

12. Hammoud B, Ndagijimana F, Faour G, Ayad H, Jomaah J (2019) Bayesian statistics of wide-band radar reflections for oil spill detection on rough ocean surface. J Mar Sci Eng 7:12. https://doi.org/10.3390/jmse7010012

13. Hansel TC, Osofsky HJ, Osofsky JD, Speier AH (2015) Longer-term mental and behavioral health effects of the deepwater horizon gulf oil spill. J Mar Sci Eng 3:1260-1271.

14. Harayama S, Kishira H, Kasai Y, Shutsubo K (1999) Petroleum biodegradation in marine environments. J Mol Microb Biotech 1(1):63-70.

15. He SJ, Yu HJ, Luo YM, Wang CY, Li XS, Li ZP (2018) Oil mixing behavior after an oil spill: identification conflicts of different fingerprints. Environ Sci Pollut R 25(10): 9539-9546. https://doi.org/10.1007/s11356-018-1257-2

16. Hua Y, Mirnaghi FS, Yang Z, Hollebone BP, Brown CE (2018) Effect of evaporative weathering and oilsediment interactions on the fate and behavior of diluted bitumen in marine environments. Part 1. Spill-related properties, oil buoyancy, and oil-particulate aggregates characterization. Chemosphere 191:1038-1047. https://doi.org/10.1016/j.chemosphere.2017.10.156

17. IMO (2012) Operational guidelines on sunken and submerged oil assessment and removal techniques. International Maritime Organization: London

18. Jacqueline M (2008) Spills of nonfloating oil: Evaluation of response technologies. Int Oil Spill Conf Proc 261-267.

19. Khelifa A, Fingas M, Brown C (2008) Effects of dispersants on oil-spm aggregation and fate in us coastal waters. Final Report.

20. Khelifa A, Stoffyn-Egli P, Hill PS, Lee K (2005) Effects of salinity and clay type on oil-mineral aggregation. Mar Environ Res 59(3):235-254. https://doi.org/10.1016/j.marenvres.2004.05.003

21. Kujawinski EB, Soule MCK, Valentine DL, Boysen AK, Longnecker K, Redmond, MC (2011) Fate of dispersants associated with the deepwater horizon oil spill. Environ Sci Technol 45(4):1298-1306. https://doi.org/10.1016/10.1021/es103838p

22. Lambert RA, Variano EA (2016) Collision of oil droplets with marine aggregates: Effect of droplet size. J Geophys Res-Oceans 121(5):3250-3260. https://doi.org/10.1002/2015jc011562

23. Li H, Bao M, Li Y, Zhao L, King T, Xie Y (2020) Effects of suspended particulate matter, surface oil layer thickness and surfactants on the formation and transport of oil-sediment aggregates (OSA). Int 
Biodeter Biodegr 149. https://doi.org/10.1016/j.ibiod.2020.104925

24. Li Z, Kepkay P, Lee K, King T, Boufadel MC, Venosa AD (2007) Effects of chemical dispersants and mineral fines on crude oil dispersion in a wave tank under breaking waves. Mar Pollut Bull 54(7):98393. https://doi.org/10.1016/j.marpolbul.2007.02.012

25. Li Z, Lee K, King T, Boufadel MC Venosa AD (2008) Assessment of chemical dispersant effectiveness in a wave tank under regular non-breaking and breaking wave conditions. Mar Pollut Bull 56(5):90312. https://doi.org/10.1016/j.marpolbul.2008.01.031

26. Li Z, Spaulding M, McCay DF, Crowley D, Payne JR (2017) Development of a unified oil droplet size distribution model with application to surface breaking waves and subsea blowout releases considering dispersant effects. Mar Pollut Bull 114(1):247-257.

https://doi.org/10.1016/j.marpolbul.2016.09.008

27. Liu J, Wang D, Teng Z (2011) The persistence and global attractivity in general nonautonomous discrete single-species Kolmogorov model with delays. J Math Anal Appl 378:403-417. https://doi.org/10.1016/j.jmaa.2011.01.058

28. Loh A, Shankar R, Ha SY, An JG Yim UH (2020) Stability of mechanically and chemically dispersed oil: Effect of particle types on oil dispersion. Sci Total Environ 716. https://doi.org/10.1016/j.scitotenv.2019.135343

29. Loh A, Shim WJ, Ha SY, Yim UH (2015) Oil-suspended particulate matter aggregates: Formation mechanism and fate in the marine environment. Ocean Sci J 49(4):329-341. https://doi.org/10.1007/s12601-014-0031-8

30. Loh A, Yim UH (2016) A review of the effects of particle types on oil-suspended particulate matter aggregate formation. Ocean Sci J 51:535-548. https://doi.org/10.1007/s12601-016-0050-8

31. McNutt MK, Camilli R, Crone TJ, Guthrie GD, Hsieh PA, Ryerson TB, Savas O, Shaffer F (2012) Review of flow rate estimates of the Deepwater Horizon oil spill. Proceedings of the National Academy of Sciences of the United States of America 109(50):20260-20267. https://doi.org/10.1073/pnas.1112139108

32. Moreira ÍTA, Oliveira OMC, Silva CS, Rios MC, Queiroz AFS, Assunçăo RV, Carvalho APN (2015) Chemometrics applied in laboratory study on formation of oil-spm aggregates (OSAs) - a contribution to ecological evaluation. Microchem J 118:198-202. https://doi.org/10.1016/j.microc.2014.09.007

33. Murtaza M, Khan RA, Kamal MS, Hussain SMS, Mahmoud M (2020) Poly(Oxyethylene)-amidoamine based gemini cati-onic surfactants with hydrophilic spacers as clay stabilizers. Energ Fuel 34:1061910630. https://doi.org/10.1021/acs.energyfuels.0c01010

34. Page CA, Bonner JS, Sumner PL, Mcdonald TJ, Autenrieth RL, Fuller CB (2002) Behavior of a chemically-dispersed oil and a whole oil on a near-shore environment. Water Res 34:2507-2516. https://doi.org/10.1016/S0043-1354(99)00398-X

35. Prince, RC, Butler JD (2014) A protocol for assessing the effectiveness of oil spill dispersants in stimulating the biodegradation of oil. Environ Sci Pollut R 21(16):9506-9510. 
https://doi.org/10.1007/s11356-013-2053-7

36. Qi Z, Sun R, Yu Y, Xiong D, Li W, Yu X, Fu S (2021) Performance of dispersed oil and suspended sediment during the oil-sediment aggregation process. Mar Pollut Bull 168:112455. https://doi.org/10.1016/j.marpolbul.2021.112455

37. Qi Z, Yu Y, Yu X, Li W, Fu S, Xiong D (2020) Effect of the concentration and size of suspended particulate matter on oil-particle aggregation. Mar Pollut Bull 153:8. https://doi.org/10.1016/j.marpolbul.2020.110957

38. Qi Z, Zhang C, Han J, Gao Y, Xiong D (2018) A decision model responding to the refuge request from a ship in need of assistance. Mar Policy 95:294-300. https://doi.org/10.1016/j.marpol.2018.05.027

39. Shen X, Maa JPY (2017) Floc size distributions of suspended kaolinite in an advection transport dominated tank: measurements and modeling. Ocean Dyn 67:1495-1510. https://doi.org/10.1007/s10236-017-1097-5

40. Shi L, Liu C, Chen M, Hua Z, Ye Z, Zhang J (2021) Synthesis and evaluation of a hyperbranched copolymer as viscosity reducer for offshore heavy oil. J Pet Sci Eng 196. https://doi.org/10.1016/j.petrol.2020.108011

41. Silva CS, de Oliveira OMC, Moreira ITA, Queiroz AFS, de Almeida M, Silva JVL, Andrade IOD (2019) Potential application of oil-suspended particulate matter aggregates (OSA) on the remediation of reflective beaches impacted by petroleum: a mesocosm simulation. Environ Sci Pollut $\mathrm{R}$ 26(18):18071-18083. https://doi.org/10.1007/s11356-015-5234-8

42. Sorensen L, Melbye AG, Booth AM (2014) Oil droplet interaction with suspended sediment in the seawater column: Influence of physical parameters and chemical dispersants. Mar Pollut Bull 78(12),146-152. https://doi.org/10.1016/j.marpolbul.2013.10.049

43. Suneel V, Kumar SS, Balaji R, Vethamony P (2021) Formation and weathering assessment of oilsuspended sediment aggregates through a laboratory investigation. Environ Sci Pollut $R$ 28(14):17181-17199. https://doi.org/10.1007/s11356-020-11813-w

44. Usher D (2009) Method and apparatus for subsurface oil recovery using a submersible unit. U.S. Patent US7597811.

45. Yoon IH, Jung CH, Yoon SB, Park SY, Moon JK, Choi WK (2014) Effect of silica nanoparticles on the stability of decontamination foam and. their application for oxide dissolution of corroded specimens. Ann Nucl Energy 73:168-174. https://doi.org/10.1016/j.anucene.2014.06.046

46. Yu Y, Qi Z, Fu S, Yu X, Li W, Xiong D (2019) Effects of wave conditions and particle size on the release of oil from oil-contaminated sediments in a wave tank. J Mar Sci Eng 7(8):256. https://doi.org/10.3390/jmse7080256

47. Yu Y, Qi Z, Xiong D, Sun R, Fu S, Li W (2021) Oil dispersion and aggregation with suspended particles in a wave tank. J Environ Manage 278(Pt2):111572. https://doi.org/10.1016/j.jenvman.2020.111572

48. Yu Y, Qi Z, Li W, Fu S, Yu X, Xiong D (2019) Effects of physical parameters and chemical dispersant on the formation of oil-particle aggregates (OPAs) in marine environments. Mar Pollut Bull 148:6674. https://doi.org/10.1016/j.marpolbul.2019.07.069 
49. Zhao L, Boufadel MC, Katz J, Haspel G, Lee K, King T, Robinson B (2017) A new mechanism of sediment attachment to oil in turbulent flows: projectile particles. Environ Sci Technol 1:1102011028. https://doi.org/10.1021/acs.est.7b02032

\section{Figures}

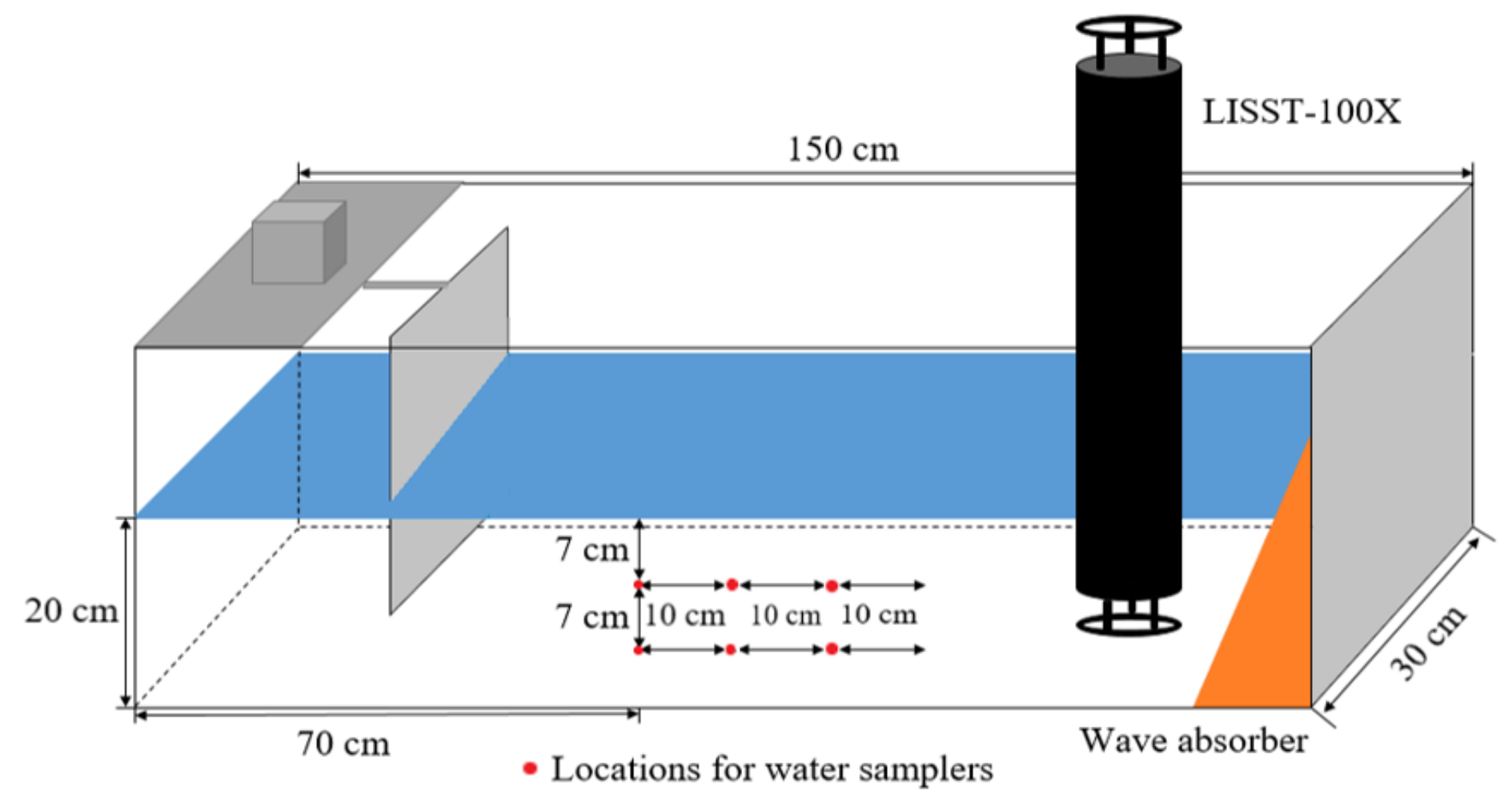

Figure 1

Schematic representation of the mesoscale tank facility 


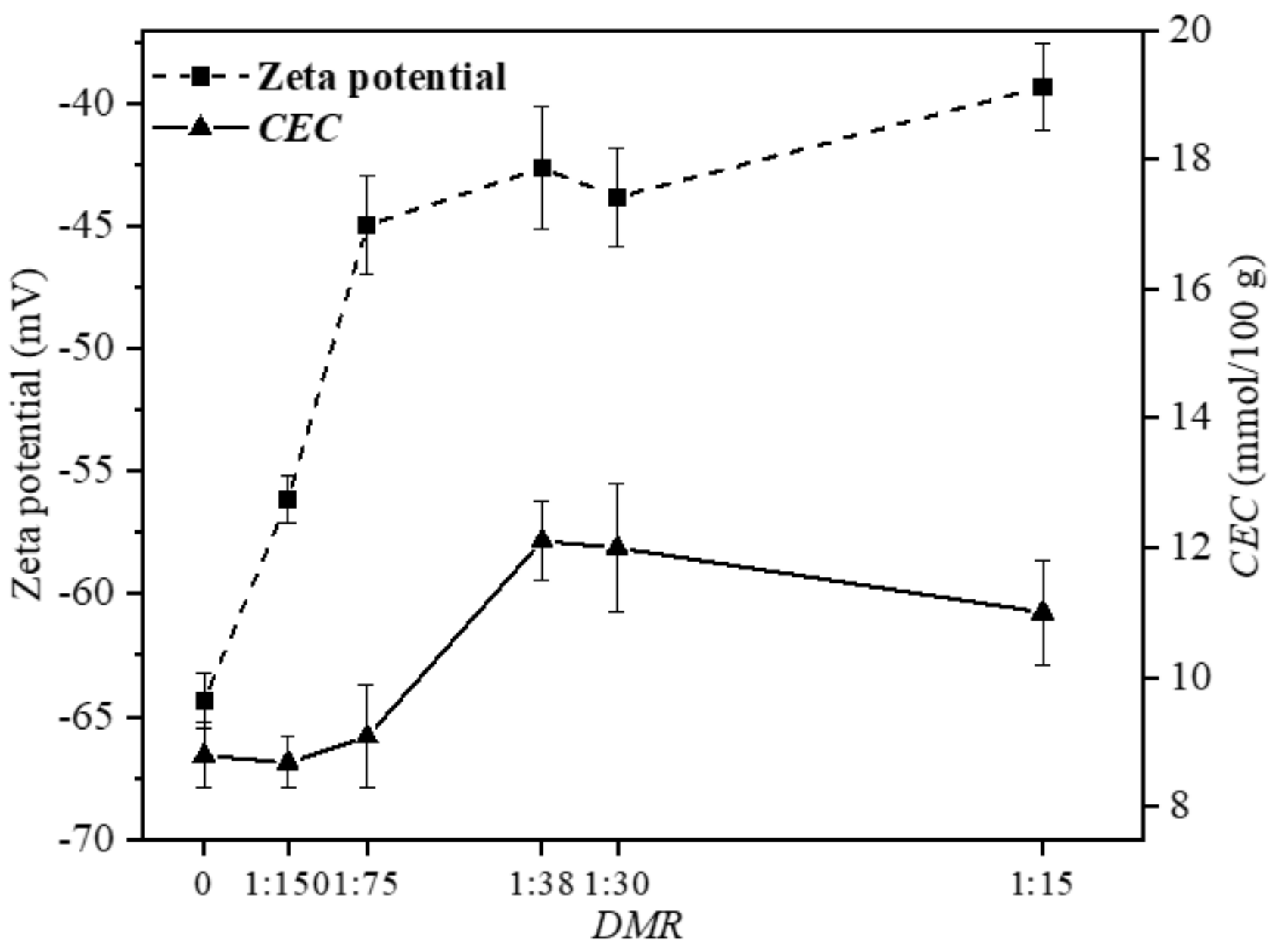

Figure 2

Zeta potential and CEC of kaolin particles at different DMR 


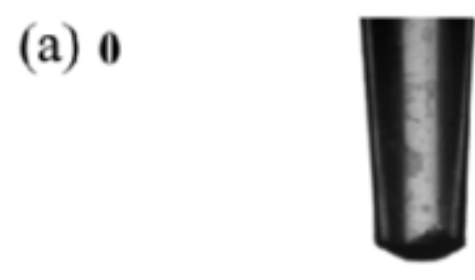

(b) 1:150
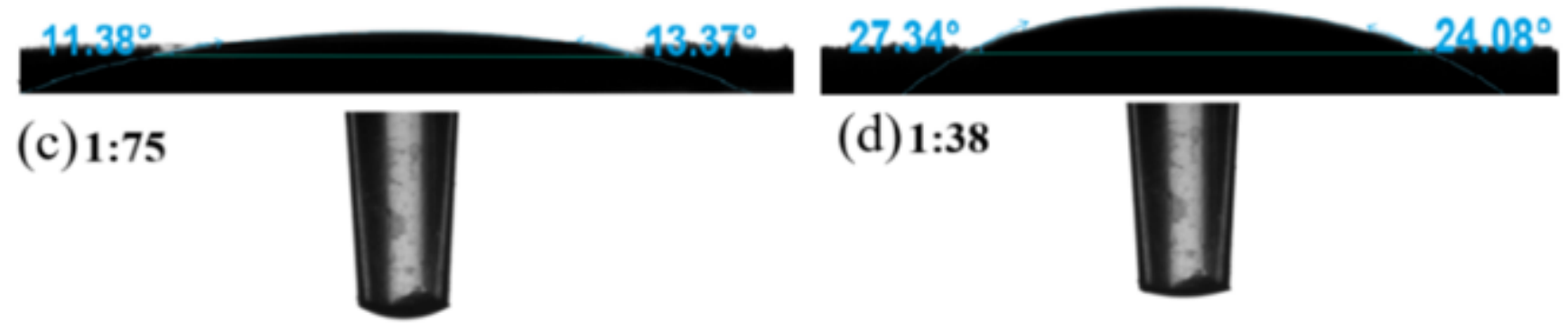

(d) 1:38
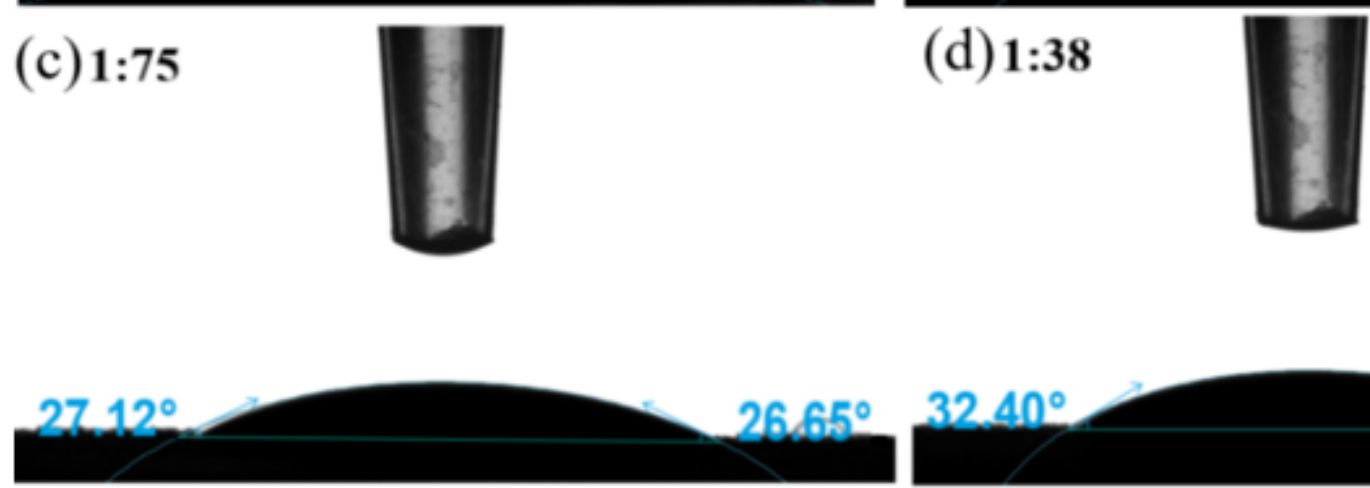

(e) 1:30
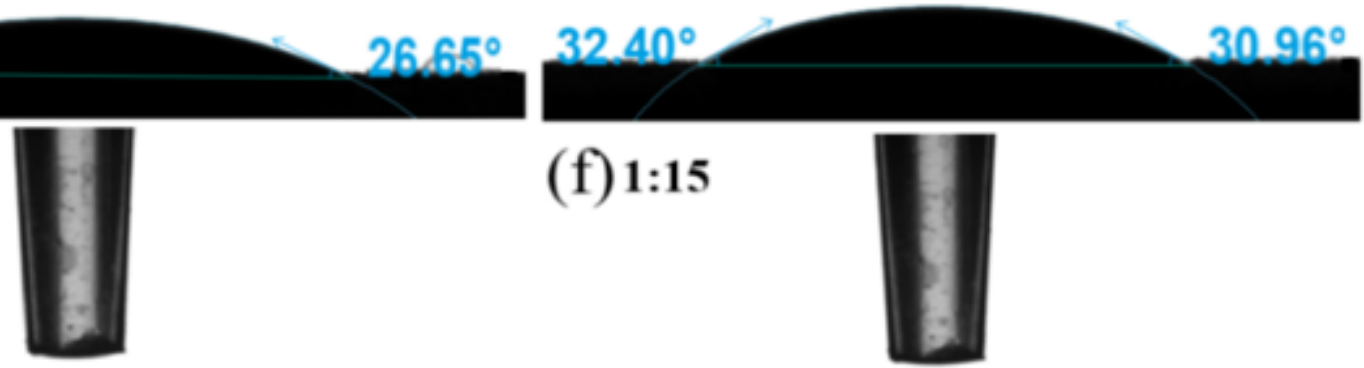

(f) 1:15
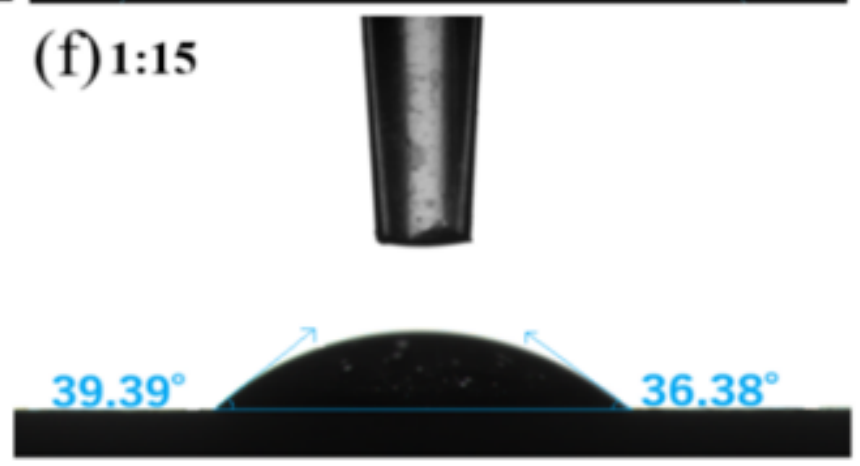

Figure 3

Change of contact angle of kaolin after wetted by different dosages of dispersant: DMR was (a) 0 , (b) 1:150, (c) 1:75, (d) 1:38, (e) 1:30 and (f) 1:15 

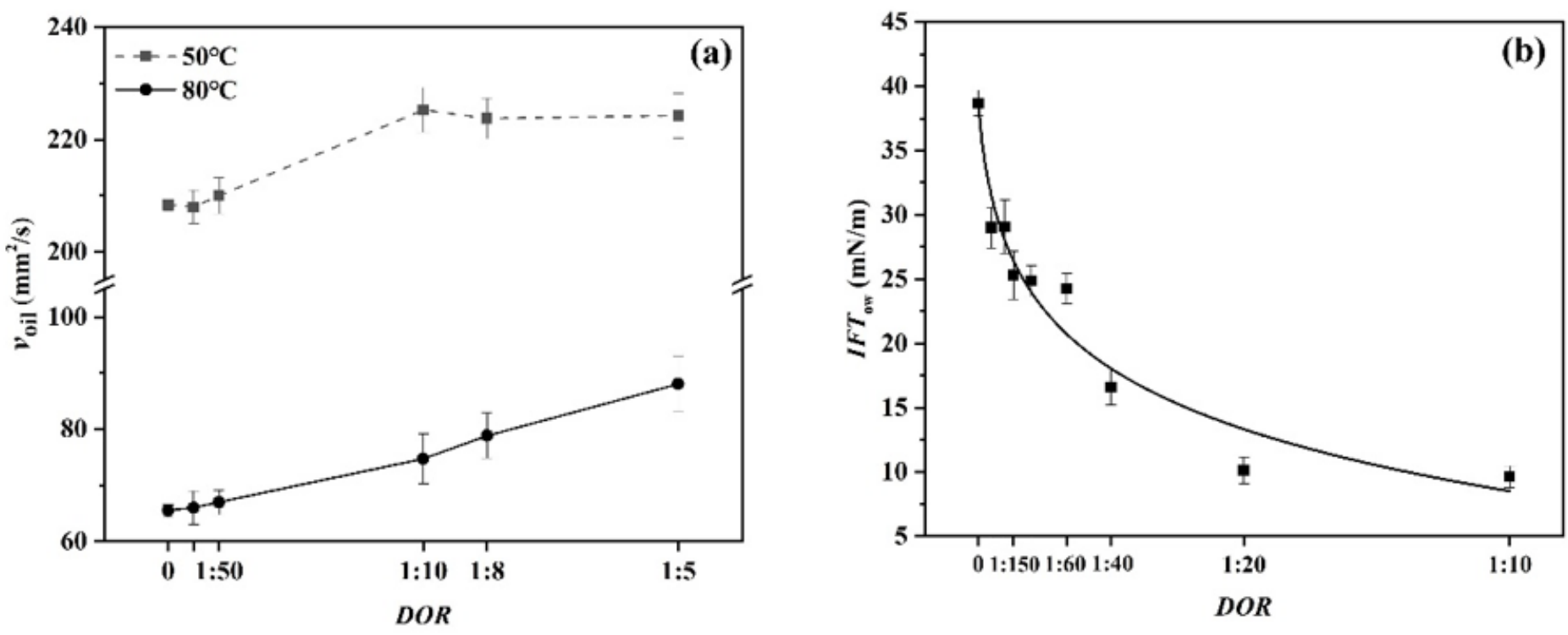

Figure 4

Characteristic change of Roncador crude oil after spraying different dosages of dispersant: (a) oil viscosity and (b) oil-water interfacial tension

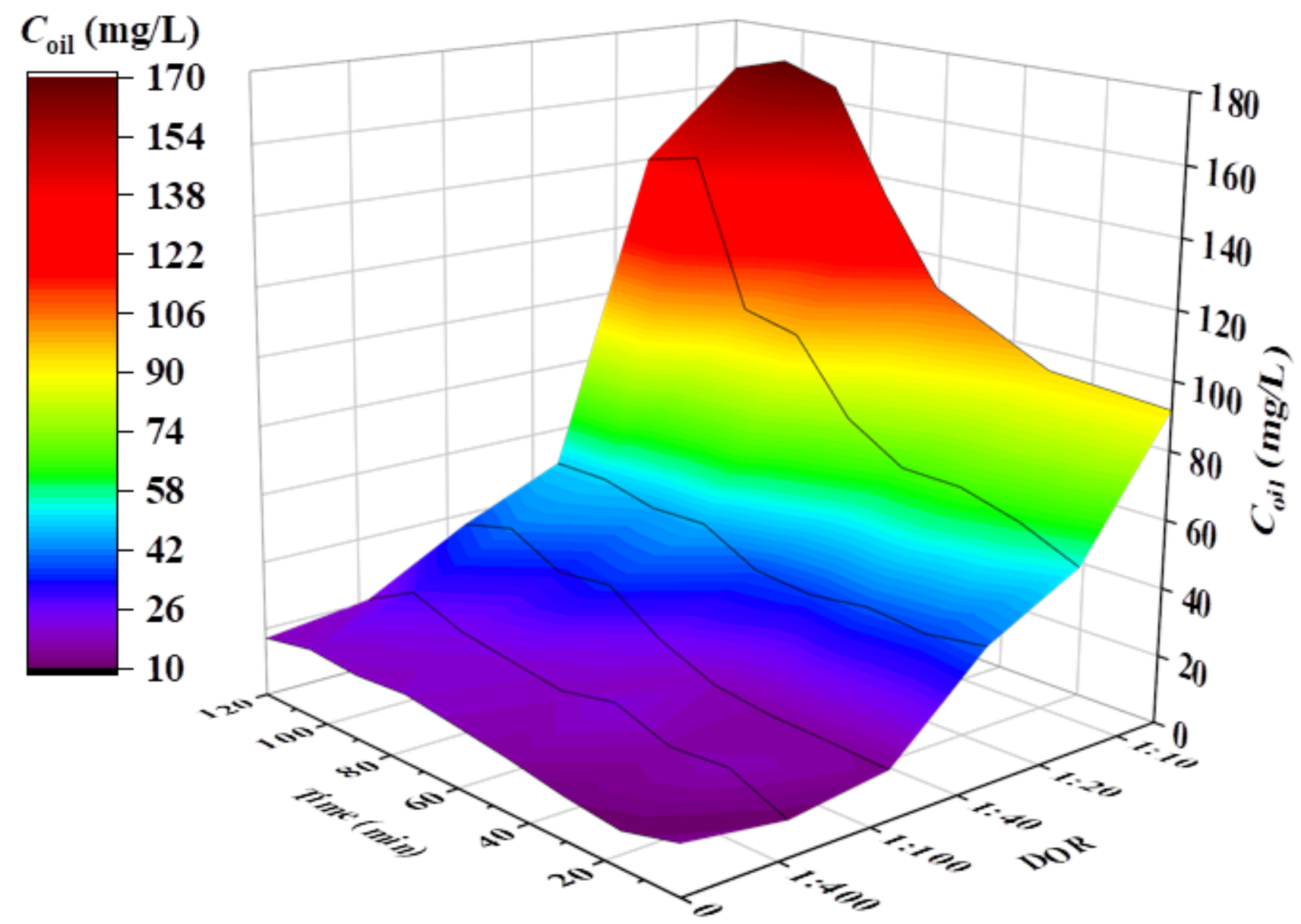

Figure 5 
Variation of oil concentration with time at different DOR

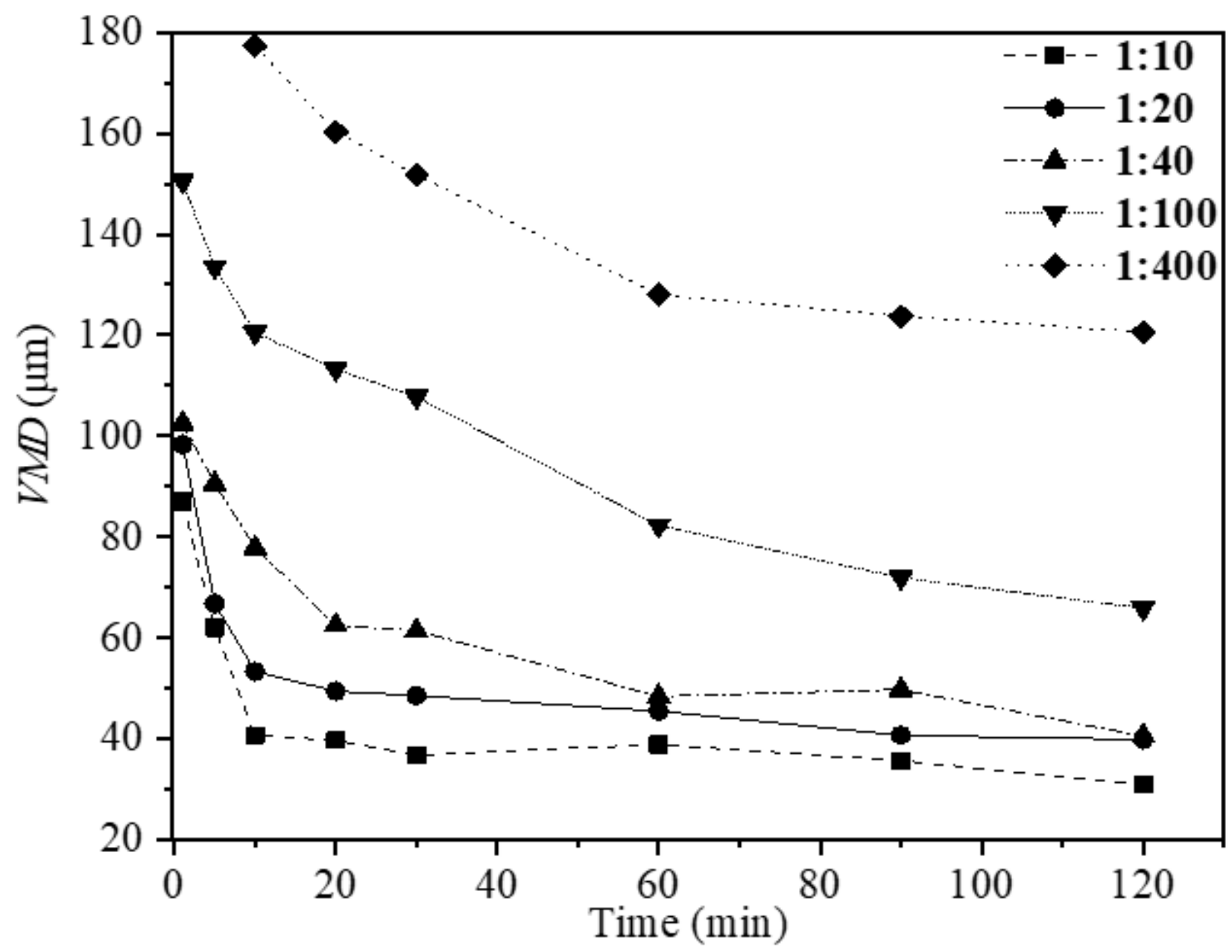

Figure 6

Variation of VMD with time at different DOR 

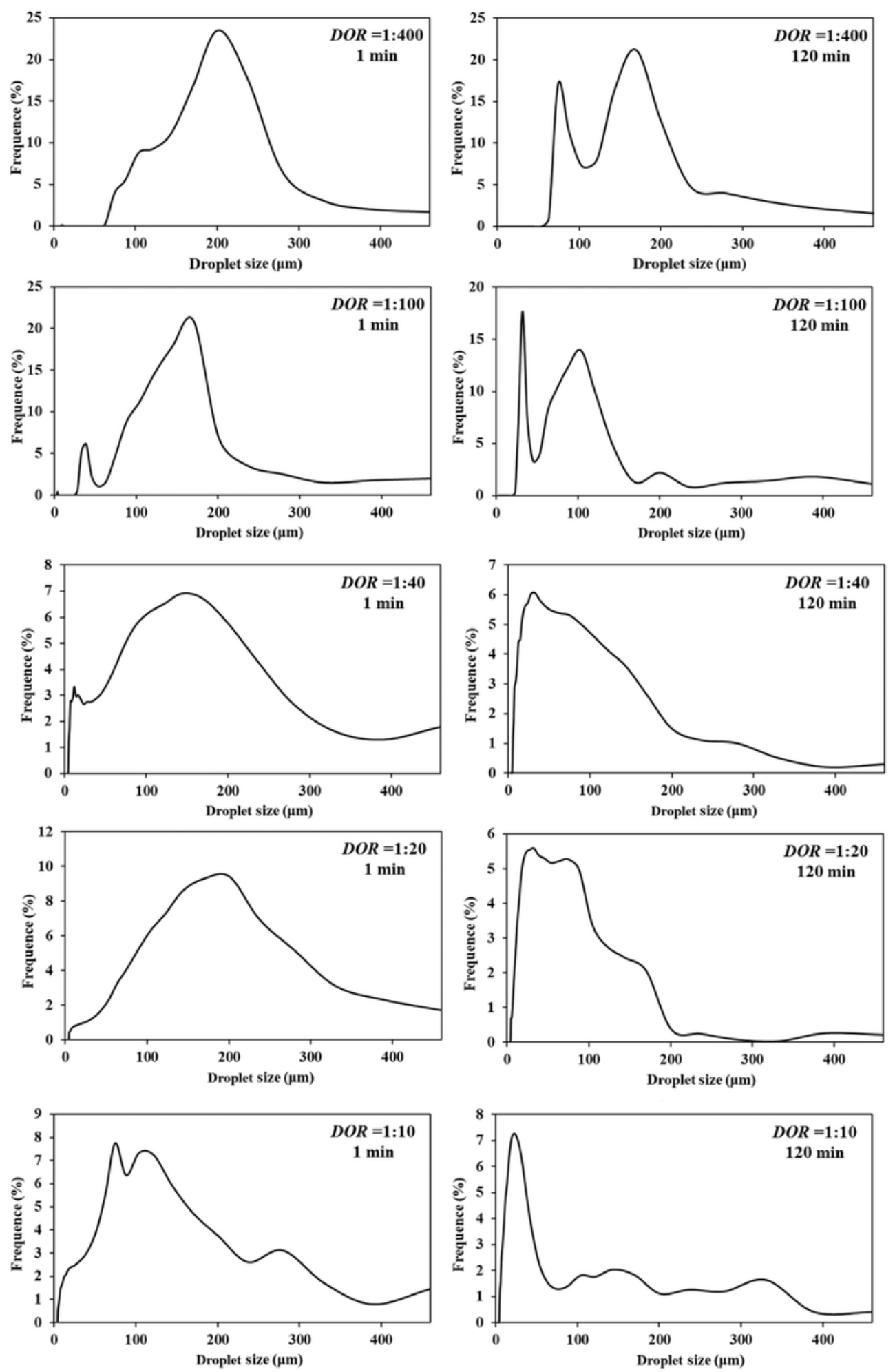

Figure 7

Oil droplets size distribution at different time and DOR 


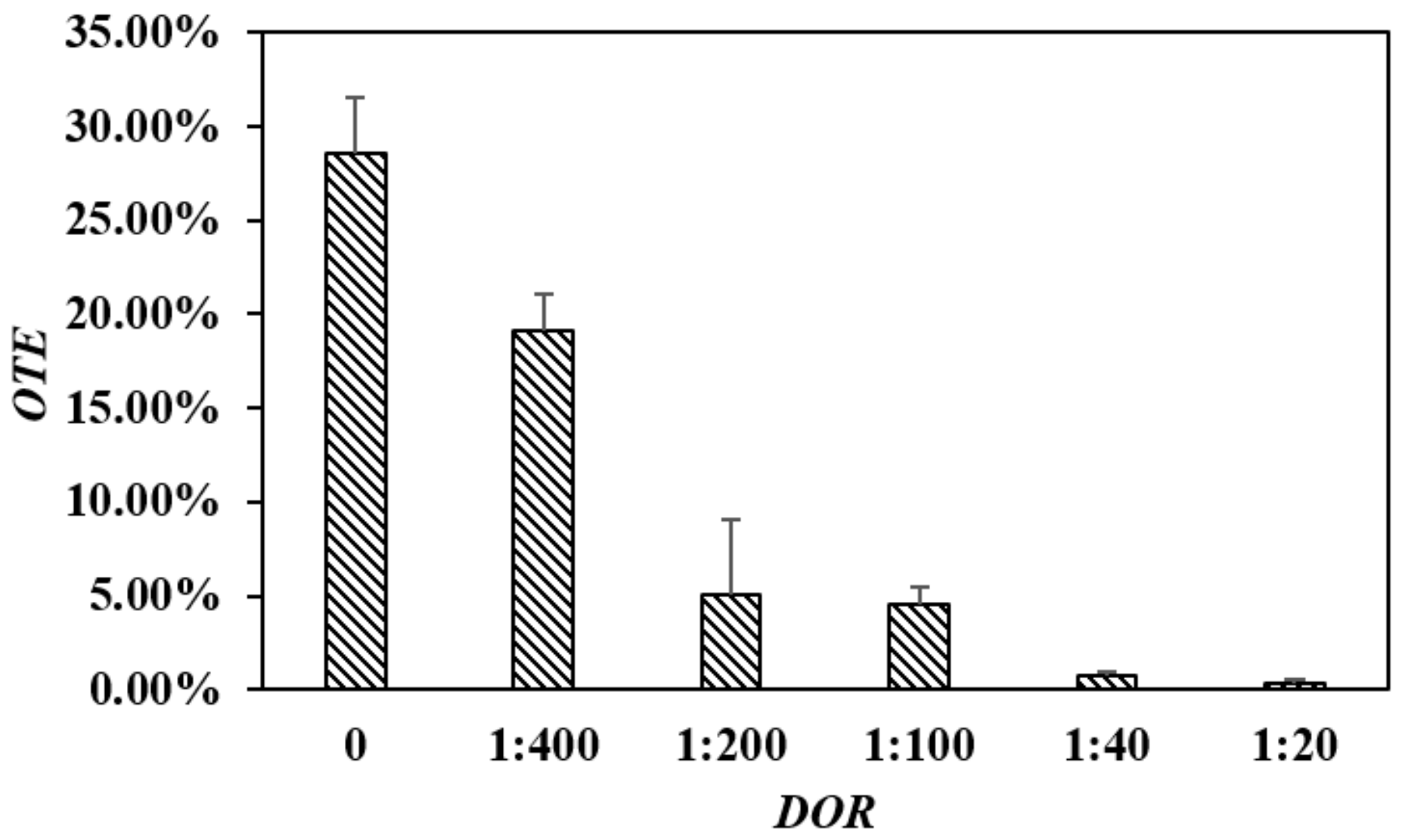

Figure 8

Variation of OTE with DOR 